\title{
Malaria treatment in Northern Ghana: What is the treatment cost per case to households?
}

\author{
James Akazili MA ${ }^{1}$, Moses Aikins² ${ }^{2}$ Fred N. Binka ${ }^{3}$ \\ 1. Navrongo Health Research Centre, P.O. Box 114, Navrongo, Ghana.Office tel: (+233)-742-22651 Home tel: \\ (+233) 244834435 Fax: (+233)-742-22320 E-mail: akazjames@yahoo.com/akazilij01@hotmail.com \\ 2. JSA Consultants Ltd. P. O. Box A408, La, Accra, Ghana.Tel: (+233)-21-779344 Fax: (+233)-21-779345,Email: \\ maikins@jsaconsultants.com. 3. School of Public Health, University of Ghana, Legon, Accra, Ghana. Tel: (+233- \\ 208131031 Fax: (+233-21-500388, Email:fbinka@,sph.ug.edu.gh
}

\section{SUMMARY}

\begin{abstract}
Although malaria is a major problem in Sub-Saharan African countries including Ghana, there has been little research on its economic impact, particularly the treatment cost at the household level. This study uses data collected from a random sample of 423 households in Kassena-Nankana district (KND) of northern Ghana. Malaria was ascertained through selfreporting of symptoms using a one-month recall period. The paper presents treatment cost analysis of seeking malaria care to households. Direct and indirect costs to households are estimated and examined in terms of location, severity, and wealth. The study shows that indirect cost accounts for 71 percent of total cost of a malaria episode. While cost of malaria care is estimated at 1 percent of the income of the rich, it is 34 percent of the poor households' income, suggesting that the burden of malaria is higher for poorer households. In order to reduce the cost of malaria to households, we recommend that the training of malaria volunteers to assist households in the communities to take more responsibility of the disease and also to intensify public education to promote the use of insecticide treated nets, as they have been found to be cost-effective in the prevention of malaria.
\end{abstract}

[Afr J Health Sci. 2007; 14:70-79]

\section{Introduction}

Malaria remains the most important vectortransmitted human disease [1]. It has been and remains an epidemic in most parts of Sub-Saharan Africa. Malaria is a primary cause of poverty in Africa and the human suffering and economic burden has reached unacceptable levels [2]. The cost of malaria in economic terms is also high: treatment cost ranges between US\$ 0.80 and US\$ 5.30 depending on local antimalarial drug and the total cost to Africa is estimated at US\$1.8 trillion per year [3]

A number of studies have examined the direct and indirect costs of an episode of malaria [4, 5, 6, 7, 8 , 9]. Households incur additional costs to treat episodes outside the formal health system, which can be a substantial proportion of households' income especially among the poor. In Ghana, malaria is said to be the major cause of mortality especially in young children [10] In 1981, the Ghana Health Assessment Team considered malaria to be the highest cause of loss of number of days in healthy and productive life in Ghana.
Several malaria studies have been undertaken in the KND, all of which indicate that malaria remains a major health problem $[10,11,12]$. Recent data from the district hospital indicated that malaria remains the commonest reason for seeking medical care among all age groups and also the leading causes of the loss of days of healthy and productive life. However, no study has been conducted to estimate the cost of malaria in the KND. This study intends to contribute to filling this gap by assessing the treatment cost of malaria in a rural and deprived area of northern Ghana which is geographically, socio-economically and culturally different from southern Ghana where Asenso-Okyere and Dwator [4] study was conducted and where malaria transmission is all-year round.

\section{The setting}

The KND, is a rural district in the Upper East region on the northern border of Ghana and Burkina Faso. The district covers an area of $1,675 \mathrm{~km}^{2}$ and has about 143,000 people. The population is mostly rural, and settlements are dispersed [12]. There is one major town, Navrongo, where about 10 percent of the 
people live. There are two main ethnic groups: the Kassenas and the Nankanas and a minority Builsa and settlers from the other parts of the country. The main occupation in the district is subsistence farming and livestock rearing. KND is in the poorest region of Ghana where $88 \%$ (more than doubles the figures in southern Ghana) of people live below the poverty line [13]

The KND lies in the Guinea-Sudan Savannah transition zone and is characterized by a dry climate with a single rainfall regime ${ }^{1}$ and two distinct seasons: the dry and wet seasons. Mean temperatures range from a minimum of $20^{\circ} \mathrm{C}$ to a maximum of $42^{\circ} \mathrm{C}$. These conditions are favourable to mosquito breeding leading to relatively high malaria incidence.

The KND has few modern health infrastructures one hospital and four health centers - that provide curative and preventive health care. There are also a number of chemical and drug shops in the urban and the rural parts of the district. The KND is home to the Navrongo Health Research Centre (NHRC), a research station of the Ghana Health Service that has the mandate to develop and test primary health care strategies among other health issues in the northern belt of Ghana. Over the years, malaria has topped the list of the 10 top diseases in the district. Thus, it is important to examine malaria treatment cost to households in order to better understand the burden of malaria to households.

\section{Conceptual framework of the study}

There are both direct and indirect costs associated with malaria treatment. Quantifying the opportunity cost of the time involved in seeking health care, which is defined as the "value of the output foregone for not using the time in its next best alternative" [14] is important to provide an overview of the total economic cost incurred by households in seeking malaria treatment.

As Castro and Mokate [15] noted, costs of diseases including malaria can be analysed either from a macroeconomic or microeconomic perspective. The macroeconomic analysis is through the evaluation of national control programmes in relation to national product while the microeconomic analysis considers the impact of the disease on individuals and households. The availability of macroeconomic cost data can aid in health planning and cost effectiveness analysis and whilst knowledge of the microeconomic costs are useful in assessing the ability of individuals and households affordability of health care services.

\footnotetext{
71

${ }^{1}$ This is unique to northern Ghana compared with southern Ghana where rains come twice in a year.
}

In evaluating the economic consequences of malaria at the household level, the resource implications of mortality and morbidity need to be considered. In the absence of health insurance or other governmentsupported services, expenditures on health care are wholly borne by individuals, and/or their households [16]. Even when cash expenses are not involved, there is an opportunity cost of time spent in seeking treatment or being unable to work because of the debility caused by the disease. Both the direct and indirect costs can be analysed either from the perspective of the individual, household or society as a whole.

\section{Materials and Methods}

Table 1 shows the range of costs identified, measured, and valued. These costs can be classified into direct, indirect, and intangible costs.

\section{a) Direct costs}

Direct costs included all cash expenditures on seeking malaria treatment by patients and their caretakers. The components of the direct cost included cash expenditure on special food, transportation, medical supplies, non-medical supplies, services, and all other out-of-pocket expenditures made on seeking malaria treatment by malaria patients and their caretakers.

\section{b) Indirect cost}

The indirect costs are mainly treatment, waiting, and travel times. There is an opportunity cost to time used since time can either be used for productive activities or leisure [9]. Time is considered as a scarce resource and could be valued at the marginal product of labour (MPL) and marginal cost of labour (MCL), which is usually used by economists to evaluate the opportunity cost of time. Regarding school absenteeism due to malaria, Malaria has life-long effects on cognitive development and education levels caused by malaria-induced anaemia and time lost to illness in the classroom [17]. The level and quality of one's education could affect one's income.

\section{c) Intangible cost}

The intangible impact of malaria is defined in relation to its impact on the quality of life [9]. Health is consumption and an investment good. As consumption good, it is a characteristic valued in its own right. Like better food or better housing, better health is an attribute that increases its owner's quality of life. The investment nature of health is directly linked with productivity and output as a result of good health [18]. Malaria affects the quality of life of the victims as it can reduce the desire to consume 
food and other resources for a happy and enjoyable life. These forgone consumption and pleasures are rather difficult to measure and quantify. Intangible costs although recognized as being important, were not considered in this paper.

Table 1. Sources and effects of economic costs of malaria

\begin{tabular}{|l|l|l|}
\hline Type & Source & Effect \\
\hline Direct costs & $\begin{array}{l}\text { Treatment and prevention } \\
\text { (i.e. mortality, morbidity \& debility) }\end{array}$ & $\begin{array}{l}\text { Expenditure of households and } \\
\text { governments }\end{array}$ \\
\hline Indirect costs & $\begin{array}{l}\text { Treatment time, waiting time and } \\
\text { travel time }\end{array}$ & $\begin{array}{l}\text { Economic output (e.g. crop } \\
\text { production) }\end{array}$ \\
\hline Intangible effects & Health status & Quality of life \\
\hline
\end{tabular}

Source: Adapted from Shepard et al. (1991)

\section{Method of measuring and valuing costs a) Direct cost estimation}

The reference year for all costs in this study is 2000 and was calculated in Ghanaian currency, the cedi $(\phi)$. The official inter-bank exchange rate at the time was $\notin 3,750$ to US $\$ 1$. In this study, the direct cost of malaria treatment included all cash expenditures on seeking malaria care by patients and their caretakers. This includes all cash expenditure on special food, transportation, medical supplies, non-medical supplies, services, and all other out-of-pocket expenditures incurred on seeking malaria care by malaria patients and their caretakers. These costs were recorded on the questionnaire as reported by the respondent. In cases where respondents could not recall the specific amounts of the out-of-pocket or direct cost components, lump sums were recorded, and this was within a recall period of one month. In cases where receipts of purchase were available, they were crosschecked with the verbally reported figures. This helped to reconcile some of the figures reported. All direct costs were then estimated. The sum of these direct costs was total expenditure for seeking malaria treatment.

\section{b) Indirect cost estimation}

Lipsey et al. [18] defines the MPL and MCL as follows: (MPL is the output as a result of engaging an additional labour input in production whereas the MCL is the additional cost of as result of an additional labour input in production. Therefore, time considered as a scarce resource, was valued at MPL. The concept of MCL was used to evaluate the opportunity cost of time. In subsistence agriculture society such as the KND with easily available land, labour is by far the most important input variable to production, and MCL can be approximated by the
MPL. Therefore, the MPL relates the market value of output to the amount of labour resource used in the production process. In maximization situation, labour will be hired up to the point where MCL is equal to MPL, and MPL is equal to the wage rate.

In computing the indirect costs in this study, the following assumptions were made. First, the adult working force comprises all people from age 18-60 years, which corresponds to the age of maturity and retirement in Ghana respectively. Secondly, children under 12 years of age were formally not in employment, which means their opportunity cost of labour was zero. Those aged 13-17 years earned halfadult male or female wage rate if they were employed. Finally, people aged 60 years and over were retired and their opportunity cost of labour was zero.

Adult malaria patients were asked how much they would have earned in a day if the malaria did not attack them. Similarly, caretakers were asked how much they would have earned per day if they did not have to take care of the malaria patients (mostly children). The mean earnings per day for both men and women did not vary much from the prevailing agricultural wage earnings in the district. Thus, the prevailing agricultural wage was used in the estimation of the indirect cost. Even though demand for agricultural labour is known to have peaks and troughs at different periods of the year [8], the agricultural wage used here was assumed to be constant because of the many other activities that tended to stabilize people's income. Besides, the agricultural wage rate did not differ significantly from the reported forgone earnings of malaria patients and caretakers. The daily agricultural wage in the district was found to be $\phi 4,500$ (US\$1.20) and $ф 4,000$ (US $\$ 1.07$ ) for male and female respectively. 
In estimating the total indirect cost that an economically active malaria patient and caretaker were absent from their normal productive activities as a result of malaria attack, the total time lost was considered for age-sex specific cases. The total waiting time and number of days lost by both malaria patients and caretakers were valued based on age and sex. The average agricultural wage, which coincided with the reported forgone daily earnings, was multiplied by the corresponding number of days lost to productivity based on age and sex.

\section{Malaria and school absenteeism}

Respondents who were attending school and reported of having had one or more episodes of malaria in the four weeks prior to the survey were asked either directly or through a caretaker, how many days they could not attend school due to the malaria episode.
The total number of school days (i.e., excluding holidays and weekends) were totaled and divided by the number of school children involved to obtain the mean days of school absenteeism for severe and mild malaria as well as rural and urban.

\section{Sampling, data analysis and ethical clearance}

The study made use of basic demographic and cluster records of the population collected by the NHRC in the district known as the Navrongo Demographic Surveillance System (NDSS).

This is a surveillance system, which is up-dated every 90 days. Basic vital demographic information such as age, sex, pregnancies, births, deaths, and migrations among others are routinely collected by the NDSS. A representative sample was drawn from the NDSS population with rural, urban, as well as ethnic representation

Table 2: Direct and indirect treatment costs by case of malaria

\begin{tabular}{|c|c|c|c|c|c|c|c|c|}
\hline \multirow{2}{*}{$\begin{array}{c}\text { Treatment } \\
\text { source }\end{array}$} & \multirow{2}{*}{$\begin{array}{l}\text { Type of } \\
\text { malaria }\end{array}$} & \multicolumn{2}{|c|}{ Cases } & \multicolumn{5}{|c|}{ Treatment cost per case (in Ghanaian currency, cedis) } \\
\hline & & $\mathrm{n}$ & $\%$ & Direct & $\%$ & Indirect $^{1}$ & $\%$ & Total \\
\hline \multirow[t]{2}{*}{ Hospital } & Severe & 16 & 3.8 & $\begin{array}{c}11,978.02 \\
(\$ 3.19)^{2}\end{array}$ & 27.5 & $\begin{array}{c}31,524.43 \\
(\$ 8.41)\end{array}$ & 72.5 & $\begin{array}{c}43,502.45 \\
(\$ 11.60)\end{array}$ \\
\hline & Mild & 40 & 9.5 & $5,636.72(\$ 1.50)$ & 34.9 & $\begin{array}{c}10,508.14 \\
(\$ 2.80)\end{array}$ & 65.1 & $\begin{array}{c}16,144.86 \\
(\$ 4.30)\end{array}$ \\
\hline \multirow[t]{2}{*}{$\begin{array}{c}\text { Health } \\
\text { center/clinic }\end{array}$} & Severe & 24 & 5.7 & $2,181.98(\$ 0.58)$ & 20.2 & $\begin{array}{c}8,617.66 \\
(\$ 2.30)\end{array}$ & 79.8 & $\begin{array}{c}10,799.64 \\
(\$ 2.88)\end{array}$ \\
\hline & Mild & 57 & 13.5 & $1,026.81(\$ 0.27)$ & 26.3 & $\begin{array}{c}2,872.55 \\
(\$ 0.77) \\
\end{array}$ & 73.7 & $3,899.36(\$ 1.04)$ \\
\hline \multirow[t]{2}{*}{$\begin{array}{l}\text { Home } \\
\text { treatment }\end{array}$} & Severe & 35 & 8.3 & $7,044.60(\$ 1.88)$ & 35.7 & $\begin{array}{c}12,706.21 \\
(\$ 3.39)\end{array}$ & 64.3 & $\begin{array}{c}19,750.81 \\
(\$ 5.27)\end{array}$ \\
\hline & Mild & 85 & 20.1 & $3,315.11(\$ 0.88)$ & 43.9 & $\begin{array}{c}4,235.40 \\
(\$ 1.13)\end{array}$ & 56.1 & $7,550.51(\$ 2.01)$ \\
\hline \multirow[t]{2}{*}{ Drug shop } & Severe & 23 & 5.4 & $3,313.07(\$ 0.88)$ & 27.2 & $\begin{array}{c}8,888.60 \\
(\$ 2.37)\end{array}$ & 72.8 & $\begin{array}{c}12,201.67 \\
(\$ 3.25) \\
\end{array}$ \\
\hline & Mild & 55 & 13.0 & $1,559.09(\$ 0.42)$ & 34.5 & $\begin{array}{c}2,962.87 \\
(\$ 0.79)\end{array}$ & 65.5 & $4,521.96(\$ 1.21)$ \\
\hline \multirow[t]{2}{*}{$\begin{array}{l}\text { Herbalist, } \\
\text { traditional }\end{array}$} & Severe & 25 & 5.9 & $2,909.71(\$ 0.78)$ & 27.0 & $\begin{array}{c}7,857.09 \\
(\$ 2.09) \\
\end{array}$ & 73.0 & $\begin{array}{c}10,766.80 \\
(\$ 2.87) \\
\end{array}$ \\
\hline & Mild & 63 & 14.9 & $1,369.27(\$ 0.36)$ & 34.3 & $\begin{array}{c}2,619.03 \\
(\$ 0.70)\end{array}$ & 65.7 & $3,988.30(\$ 1.06)$ \\
\hline Total & $\begin{array}{c}\text { All } \\
\text { cases }\end{array}$ & 423 & 100.0 & - & - & - & - & - \\
\hline $\begin{array}{c}\text { Average } \\
\text { cost }\end{array}$ & - & - & - & $7,014.65$ (\$1.87) & 29.3 & $\begin{array}{c}16,935.79 \\
(\$ 4.52)\end{array}$ & 70.7 & $\begin{array}{c}23,950.44 \\
(\$ 6.39)\end{array}$ \\
\hline
\end{tabular}

Notes: 1 - Indirect cost were estimated based on daily wage rates;

2 - Figures in parenthesis are US dollar equivalent.

A multi-stage simple random technique was used in statistically selecting 423 households in the whole district. The unit of analysis in this study was the household, which was chosen because the household rather than the individual generally operates as an economic unit in this setting. With regard to fieldwork, a training manual from the NHRC was adopted for training. The training manual gave the background of the study, aim and objectives of the study, the role of the interviewer and strategies for community entry among others. Eight fieldworkers with experience in conducting interviews with the 
NHRC were selected out of 22 fieldworkers who had just completed data collection for a similar survey. Fieldworkers were trained for two weeks on carrying out interviews. Mock interviews were also used in the training and this was followed by a carefully supervised pilot test to assess the competence of the interviewers. STATA ${ }^{\circledR} 6.0$ for Windows was used for data analysis. The analysis consisted of descriptive statistics. Ethical clearance was obtained from the Navrongo Institutional Review Board before the commencement of the study.

Table 3. Annual household expenditure by quintiles

\begin{tabular}{|l|l|l|l|}
\hline Income quintile & Social classification & Mean annual income* & Treatment cost of malaria (\%) \\
\hline Quintile 1 & Poor & $\varnothing 103,631.52(\$ 27.64)$ & 33.98 \\
\hline Quintile 2 & Less poor & $ф 392,544.60(\$ 104.69)$ & 8.97 \\
\hline Quintile 3 & Average & $\varnothing 673,843.92(\$ 179.69)$ & 5.23 \\
\hline Quintile 4 & Fairly rich & $\varnothing 1,233,034.80(\$ 328.81)$ & 2.86 \\
\hline Quintile 5 & Rich & $\$ 3,669,099.60(\$ 978.43)$ & 0.95 \\
\hline
\end{tabular}

Note: * Expenditure used as proxy for income

\section{Study limitation}

The study has some limitations. First, the study mainly focused on direct and indirect costs of seeking malaria treatment to the exclusion of intangible costs such as psychic cost, pain, and traumatism due primarily to methodological and evaluation difficulties associated with intangibles. Further, the study did not consider travel time to seek treatment for malaria patients and caretakers since anecdotal evidence suggests that travel time is not the major component of indirect cost in the district. In addition, it was difficult for respondents who were mostly illiterate to calculate the time they took to travel to seek care. Moreover, the most predominant means of traveling within the district is by foot or bicycles, which is difficult to quantify in monetary terms. Secondly, the study did not also consider the cost of malaria prevention interventions since the emphasis of the study was on cost of seeking malaria treatment. Finally, the study was also limited to self-diagnosis of malaria episode at the household levels by symptoms, rather than using a medically recorded case of malaria. However, it has been documented that the people generally have high knowledge of malaria and its associated signs and symptoms such that more than eighty percent of self-diagnosed malaria was medically confirmed positive [19]

\section{Results}

Malaria treatment sources and cost of treatment

The main treatment sources used by the community are hospital, health center/clinic, home-base care, services of drug shops, and traditional source such as herbalist and soothsayers. The treatment pattern shows that overall, around 49 percent of households used home-based care of self-medication and traditional means whereas 32 percent used the modern health facilities of hospitals and health centres/clinics and just over 18 percent of household use the services of drug shops (Figure 1).

Table 2 shows the distribution of the severity of cases by treatment sources. Nearly a half of both mild and severe cases of malaria used home-based case of self-medication and traditional sources of treatment: $35 \%$ of the mild cases and $14 \%$ of the severe cases of malaria, whilst about $10 \%$ of mild cases and $23 \%$ of severe case used modern health facilities of hospital and health centres/clinics.

\section{Average malaria treatment cost per case and per household}

Table 2 also presents the cost per case by sources of treatment and self-diagnosed severity of malaria. Cost per case is defined, as the mean cost of an episode of malaria and the cost per household is the mean cost incurred by the household on the 1.45 malaria episodes reported in the survey. The cost per household was obtained by multiplying the cost per case by average malaria cases per household (i.e., 1.45). Treatment cost was made up of direct and indirect costs. The direct costs include mainly medication and consultation in hospitals and health centres/clinics. The total cost (i.e., direct plus indirect costs) per case and total cost per household were $ф 23,949.44$, (about US\$6.39) and $\$ 35,220.15$ (about US\$9.39) respectively. There was no significant difference in the cost per case and per household by residence, apparently due to near homogeneous occupational characteristics, one main urban area and the use of almost the same health facilities by both rural and urban dwellers. The treatment cost per case ranges from $\$ 3,899.36$ (US\$1.04) in health centers/clinics to $\varnothing 16,144.86$ (US\$4.30) in hospitals for mild cases, for severe cases the cost ranges from $\notin 10,766.80$ (US\$2.87) at traditional sources to $\$ 43,502.45$ (US\$11.60) in hospitals. As expected, the treatment cost per case in hospitals and health 
centers/clinics are relatively higher than the other sources. In the case of the hospitals and health centres/clinics, some of the cases are likely to be inpatient ones since some patients were detained for a period of observation. However, some carers were unable to distinguish between the observation periods and the inpatient ones. On average, the direct cost forms 29 percent of the total average cost and the remaining 71 percent is indirect cost (Figure 2).

\section{Estimated direct cost due to malaria}

For the 423 study households, they spend a total of $\$ 4,302,193.41 \quad(\$ 1,150.35)$ as "out-of-pocket" expenditure (direct cost) in a month on malaria treatment. The average direct cost per case was $ф 10,170.67$ (US\$2.71), which was an enormous cost to households.

\section{Estimated indirect cost (productive time lost) due to malaria}

The study revealed that a total time of 2,199 days were lost to productive pursuits mainly farming and petty trading by malaria patients and their caretakers. Of these lost productive days, 62 percent were lost to women and the remaining 38 percent to men. The total estimated financial cost of this productive days lost was valued at $\not 7,163,836.90$ (US\$1,910.36). This constitutes 71 percent of the total cost of malaria treatment. On average, a household lost $₫ 16,935.79$ (US\$4.52) as an indirect cost to a malaria episode (see Figure 2). Given the average malaria case for a household of 1.45 cases, a household lost $ф 24,556.90$ (US\$6.55) as indirect cost of malaria treatment. Given the daily agricultural wage rate (forgone earnings) for men and women as $\notin 4,500$ (US\$1.20) and $\phi 4,000$ (US $\$ 1.07$ ) respectively at the time of the study, the average cost of malaria to a household in the district can then be translated into 7.7 man days (male working days) or 8.7 woman days (female working days).

Fig 1. Reported malaria treatment sources

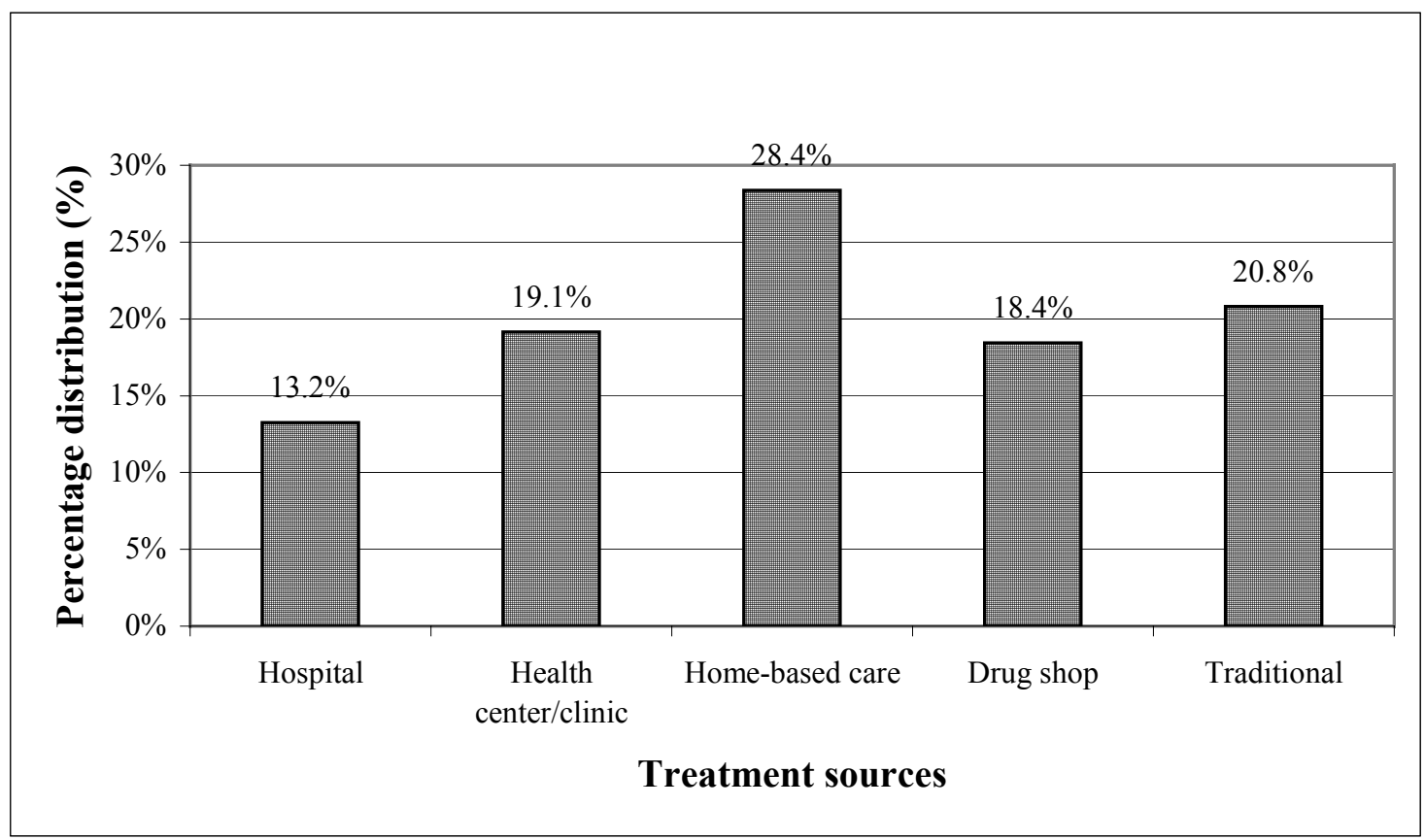

\section{Malaria treatment cost and annual household expenditures}

Annual household expenditure of the 423 households was used as a proxy to income due to the difficulty of obtaining accurate data on incomes. Five income quintiles were identified and classified with socio economic statuses. Table 3 presents the total annual household expenditure by income quintile and socioeconomic status. The total average cost per household for the malaria treatment (i.e., $₫ 35,220.15$
(US\$9.39)) was compare to each quintile. For the mean annual income of quintile 1, socioeconomically classifies as poor, malaria treatment cost to the household accounts for as much as 34 percent of the total annual household expenditure. Whilst for the rich households, malaria treatment accounts for only 1 percent of the total annual expenditure. 
Fig 2. Proportion of indirect $\&$ direct costs of malaria treatment

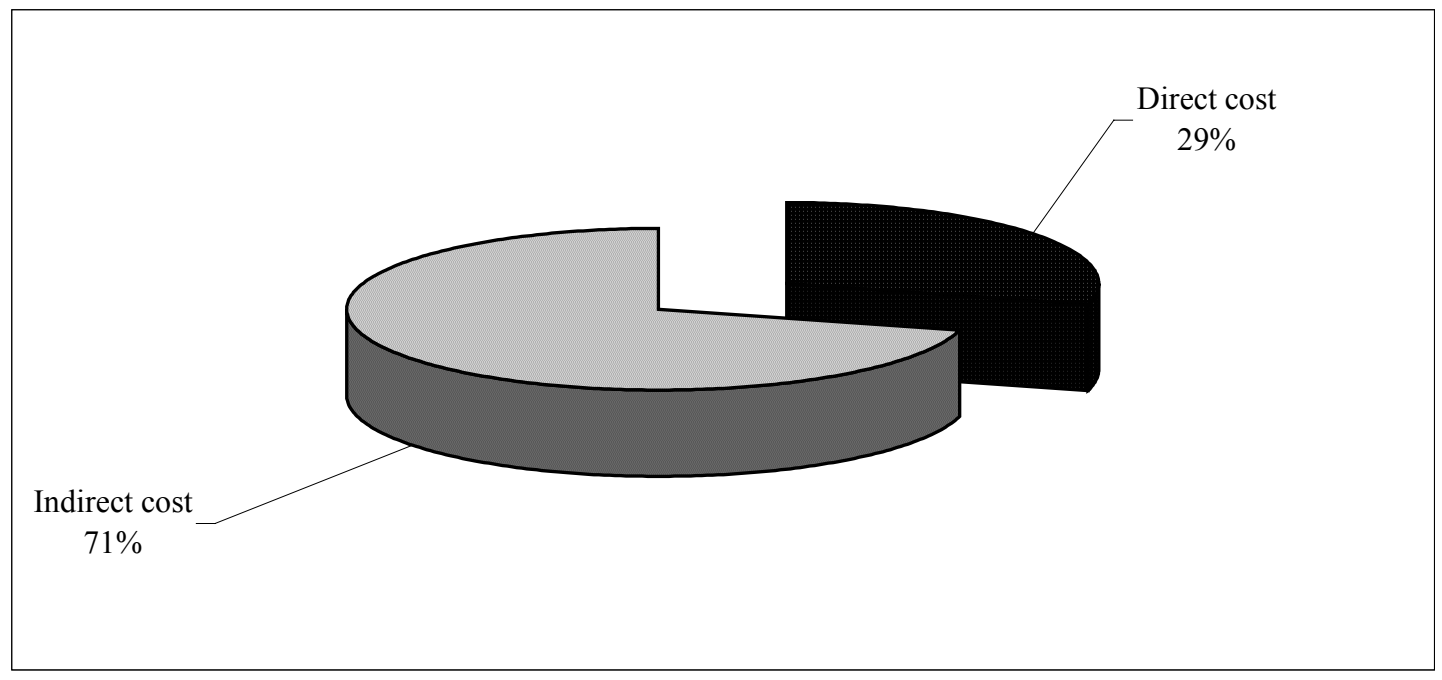

\section{Estimated school absenteeism due to malaria}

On the whole, a pupil was absent from school for 4.1 days due to a malaria episode. According to severity, a pupil lost 5.4 days from school due to severe malaria compared to 3.4 days for mild malaria. Generally, urban pupils lost on average more school days than pupils from rural areas

\section{Discussion}

Most cost analysis considers only institutional services cost [20, 21, 22], for which data is more readily available than individual, household or community costs. Such approaches overlook equally important costs, which fall outside the institutional service costs. This study attempted to identify and quantify these costs (outside institutional service costs), thereby estimating the actual costs of an episode of malaria to households. The study used the simple framework of Shepard et al [23] to estimate both direct and indirect cost of an episode of malaria to households.

The method of using the prevailing wage rate and agricultural wage rate to calculate the value of days may be robust but the problem of somebody being paid a lower wage would suggest a less value of that individual's time. The other problem of collecting information on household finances from the heads of households assuming that the household heads would have knowledge in all aspects of the household may also be erroneous since incomes are often not pooled and individuals within households are often responsible for various expenditures. The assumption of a zero opportunity cost of labour for the under 12 and over 60 years may not be entirely true and may lead to under estimation of the treatment cost to households since such individuals make substantial contributions to the overall incomes in poor agricultural households. Notwithstanding these methodological issues, the results of the study are robust and is indicative of the burden that household face in the treatment of malaria.

People resort to various sources for the treatment of malaria. Prominent of these is the home based care of self-medication and traditional treatment with herbs. With self medication people will often used reserved drugs from previous treatment and request for left over drugs from relative and friends. Thought this would be a quick way of relieve but it may not offer the necessary treatment for the malaria as some of these drugs may not be malaria related drugs or if they are, may be expired drugs. People also resort to herbs and traditional cure. The problem about traditional medicine is the dosage requirement especially those which are not scientifically tested or proven. The concoctions may not be malaria-related drugs and may even aggravate the problem of malaria. Given that nearly half of the mild and severe malaria cases resorted to these forms of treatment may suggest that malaria could continue to be recurrent problem given the ineffective treatment from self-medication and traditional treatment. Another worrying development is the purchase of drugs from local drug stores mostly without prescription. The danger is the purchase of fewer than required tablets for full treatment, which also aggravate the problem of malaria. The treatment cost of malaria could also be underestimated due to the fact that people often use multiple treatment sources for malaria treatment but may end up reporting on only the first or the last source of treatment.

As has been revealed in the study, it costs less to treat a mild malaria episode at the health centers than 
traditional treatment yet more people would sort to traditional method of treatment. This could be related to the fact that traditional religion is still widely practiced among the people and due to this the people may continue to patronize the services of traditionalists. Private providers including traditional healers continue to play a key role in the provision of healthcare services to rural communities. Eighteen percent of the malaria cases received treatment from drug peddlers. A concern regarding drug peddlers are that, they are often not adequately trained and in instances provide expired drugs and more often than not do fail to advice patients on the recommended dosage. The consequence of their activities are great since this may lead to drug resistance and repeated attacks of the diseases leading to increases in direct expenditures and the number of days lost. Integrating their services formally into the health sector stream would go a long way to improving diagnosis and treatment of malaria and other diseases.

Both direct and indirect cost were examined and average direct cost which is out-of-pocket expenditure of US\$1.87 per a malaria episode was quite substantial given that more than 80 percent of people in the region are below the poverty levels of US\$1.00 per day [13]. Indeed households may have to even borrow money or sell household assets to meet the out-of pocket expenditure on malaria. Indirect cost constitutes the lost of incomes as a result of an episode of malaria. The study revealed that more women lost a lot of productive days than men. This is expected in patriarchal society like the KND with a high male dominance where women are reduced to childbirth and childcare. The indirect cost of US\$4.52 is a very substantial lost of income to households. Substantially both men and woman lost productive working days due to malaria which otherwise would have been put to generating income or resources. However, on the average, direct cost was 29 percent of the total costs of seeking malaria care with the rest (71 percent) constituting indirect cost and this is consistent with existing literature [4, $6,9]$.

The cost of malaria could be a burden, particularly to poor households and threatens their consumption of equally important health and nonhealthcare goods. The study revealed that very lowincome households carried a disproportionate share of the economic burden of malaria. As the proportion of malaria cost to annual income was 34 percent of poor households compared to only 1 percent of the non poor households, which is a unique finding of the study.

It has also been revealed in the study that school pupils/students lost on average 4.1 days from school due to malaria. In a severe malaria case, a school pupil/student lost up to 5.4 days, which may adversely affect school attendance. Kere et al. [24] found a similar trend in the Solomon Islands. The statistics are quite disturbing since absenteeism from school could affect a child's academic performance.

\section{Conclusion}

This paper examined the total, direct, and indirect cost of the treatment of malaria in northern Ghana. The total cost of malaria per case of malaria of $\notin 23,949.44$ (US\$6.39) is quite substantial given that poverty is widespread in Ghana especially in the study region where more than half of the population live below the poverty line [13]. Many would not be able to afford the treatment of the disease and if they could, they would have to sacrifice expenditures of equally important determinants of health to treat the disease. Some may even have to sell important household assets and this could push poor households into severe poverty.

The direct or out-pocket expenditure of malaria of $\notin 7,014.65$ (US\$1.87) was 29 percent of the total cost of malaria. This is the cost that is normally felt by individuals and households as this involves direct out of pocket payment at the point of service. The cost that is normally not recognized by individuals and households is the indirect cost.

Indirect was estimated based on the number of productive days lost due to the episode of malaria. This cost was 71 percent of the total cost of malaria, which is an enormous cost. If people are made aware of this enormous loss in terms of indirect cost, perhaps they will accept more cost-effective preventive methods of malaria such as Insecticide Treated Nets (ITN), which have been found to be effective for malaria prevention [12]. The loss of days by school pupils/students due to malaria is another indirect cost but this is not financially computed. However, the long-term effect on children progress in education, human capital, and development could be grave. Perhaps, effective health education in schools on preventive measures and the need for an early response to treatment of the disease may reduce the prevalence, leading to a reduction in the overall cost.

The inequitable share of malaria cost burden to households is particularly worrying, whilst malaria cost was just $1 \%$ of the annual income of rich households, poor households bore $34 \%$ of their total annual income. This has the potential of worsening the plight of poor households and threatens their ability to effective demand for basic necessities of life. 


\section{Acknowledgements}

We acknowledge the cooperation of the chiefs, the people of the Kassena-Nankana district, and the study participants in particular. This study would not have been completed without the logistical support from the Navrongo Health Research Centre, the technical contributions of the director (Dr. Abraham Hodgson) and staff particularly Martin Adjuik, Dr. Cornelius Debpuur, Dr. Philip Adongo, Dr. Patricia Akweongo and Dr. Bawa Ayagah of the Centre, and the tireless efforts of the data collectors. We acknowledge and appreciate the comments from the anonymous reviewers of the paper and finally thanking the Almighty God for the life and sustenance.

\section{References}

1. Evans DB, Azene G, Kirigia J. Should governments subsidize the use of insecticide-impregnated mosquito nets in Africa? Implications of a cost-effectiveness analysis. Health Policy and Planning. 1997; 12: 107-114.

2. WHO/AFRO. Malaria in Africa: International conference on malaria in Africa, Dakar, Senegal. 1997.

3. Sachs J and Malaney P. The Economic and Social Burden of Malaria. Nature. 2002; 415: $680-685$.

4. Asenso-Okyere WK and Dzator JA. Household cost of seeking malaria care. A retrospective study of two districts in Ghana. Social Science and Medicine. 1997; 45: 659667.

5. Chima RI, Goodman CA and Mills A. The Economic Impact of Malaria in Africa: a critical review of the evidence. Health Policy and Planning. 2003; 63: 17-36.

6. Ettling M, McFarland DA, Schultz LJ and Chitsulo L. Economic impact of malaria in Malawian households. Tropical. Medicine and Parasitology. 1994; 45: 74-79.

7. Konradsen F, Van der Hoek W, Amerasinghe PH, Amerasinghe FP. Measuring the Economic cost of Malaria to Households in Sri Lanka, American Journal of Medicine and Hygiene. 1997; 56: 656660.

8. Sauerborn R, Shepard DS, Ettling MB, Brinkmann U, Nougtara A and Diesfeld HJ. Estimating the direct and indirect cost of malaria in a rural district of Burkina Faso. Tropical Medicine and Parasitology. 1991; 42: 219-223.

9. Shepard DS, Ettling MB, Brinkmann U and Sauerborn R. The economic cost of malaria in Africa. Tropical Medicine and Parasitology, 1991; 42: 199-203.

10. Binka FN, Maude GH, Gyapong M, Ross DA, Smith PG. Risk factors for child mortality in Northern Ghana, a case control study. International Journal of Epidemiology. 1995; 24: 127-135.

11. Binka FN, Kubaje A, Adjuik M, Williams LA, Lengeler C, Maude GH, Armah GE, Kajihara B, Adiamah JH and Smith PG. Impact of permethrin impregnated bednets on child mortality in Kassena-Nankana district, Ghana: A randomized controlled trial. Tropical Medicine and International Health. 1996; 1: 147-154.

12. Binka FN, and Adongo P. Acceptability and use of insecticide impregnated bednets in northern Ghana. Tropical Medicine and International Health. 1997; 2: 499-507.

13. Government of Ghana. Ghana Poverty Reduction Strategy 2003-2005: An Agenda for Growth and Prosperity. Volume I: Analysis and Policy Statement. 2003.

14. Konradsen F, Van der Hoek W, Amerasinghe PH, Amerasinghe FP. Measuring the Economic cost of Malaria to Households in Sri Lanka, American Journal of Medicine and Hygiene. 1997; 56: 656660.

15. Castro, EB and Mokate KM. Malaria and its Socioeconomic Meanings: the study of Cunday in Columbia. In Herrin and Rosenfield (Ed.) Economics, Health and Tropical Disease. University of Philippines, School of Economics. 1988.

16. Guiguemde TR, Dao F, Curtis V, Traore A, Sondo B, Testa J and Ouedraogo JB. Household expenditure on malaria prevention and treatment for families in the town of Bobo-Dioulasso, Burkina Faso. Transactions of the Royal Society of Tropical Medicine and Hygiene. 1994; 88: 285-287.

17. Kere NK, Keni J, Kere JF, Bobogare A, Webber RH \& Southgate BA. The economic impact of plasmodium falciparum malaria on education investment: a Pacific island case study. Southeast Asian Journal of Tropical Medicine and Public Health. 1993; 24: 659-63.

18. Lipsey RG, Steiner PO, Purvis DD, and Courant PN. Economics. (Ninth Edition). Hareper and Row, New York. 1990.

19. Owusu AS, Adongo P, Anto F and Binka FN. Conceptualisation Treatment Seeking Behaviour and compliance with Treatment 
of Malaria in a Rural Community in Northern Ghana (unpublished report) submitted to WHO/AFRO in July 1999.

20. Conly GN. The impact of malaria on economic development: A case study. American Journal of Tropical Medicine and Hygiene. 1972; 21: 668-74.

21. Creese AL and Henderson RH. Cost-benefit analysis and immunization programmes in developing countries. Bulletin of the World Health Organisation. 1980; 58: 491-497.

22. World Health Organization. World Malaria Situation in 1991. Reprinted from WHO Weekly Epidemiological Records, 1988; 34 (35).

23. Shepard DS, Ettling MB, Brinkmann U and Sauerborn R. The economic cost of malaria in Africa. Tropical Medicine and Parasitology, 1991; 42: 199-203.

24. Kere NK, Keni J, Kere JF, Bobogare A, Webber RH \& Southgate BA. The economic impact of plasmodium falciparum malaria on education investment: a Pacific island case study. Southeast Asian Journal of Tropical Medicine and Public Health. 1993; 24: 659-63. 